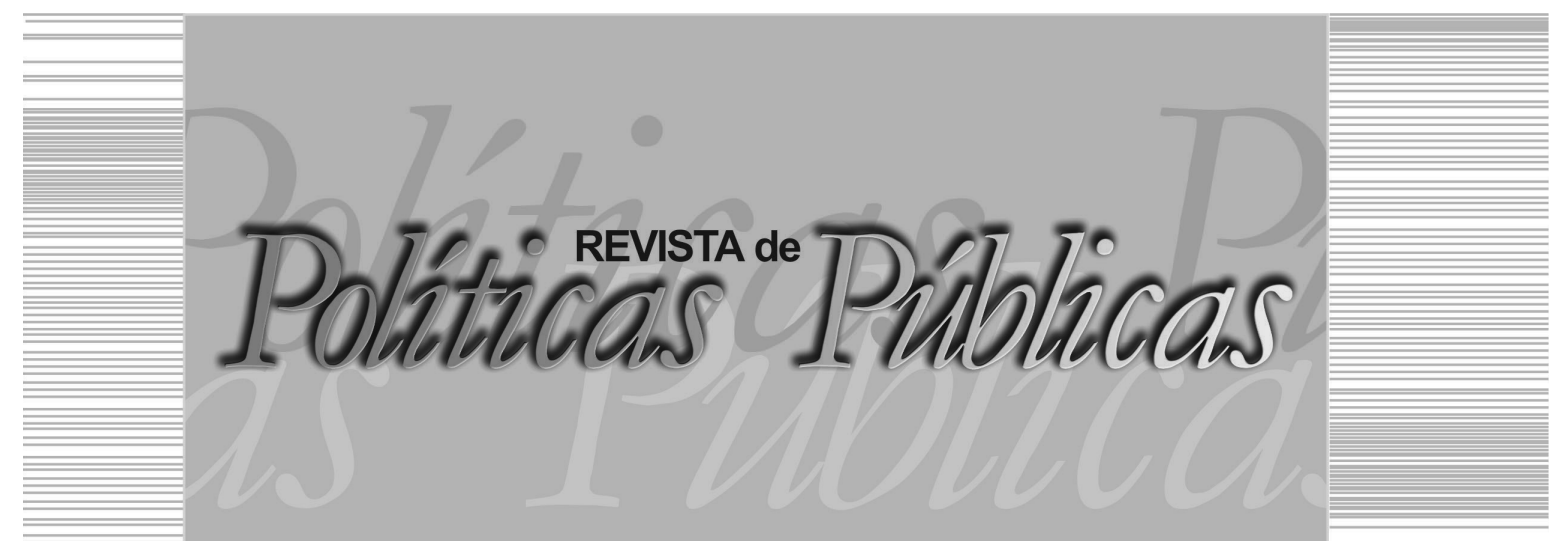

\title{
UTOPIA DA SEGURANÇA E DA PAZ EM MEIO \\ AO MEDO E AO TERROR ALIMENTADOS PELA SOCIEDADE DO CAPITAL
}

Rejane Batista Vasconcelos ${ }^{1}$

Universidade Federal do Ceará (UFC)

Faculdade Metropolitana da Grande Fortaleza (Fametro)

\section{Resumo}

Pôr em discussão as possibilidades de emergirem, de se instaurarem a segurança e a paz no interior de uma sociedade de marcos civilizatórios enraizados no medo, na violência, no terror, que faz deles ainda sua forma mais promissora de conquista, de lucro, sustentação e existência - que é a sociedade capitalista -, é o que este artigo tem por fim último alcançar.

Palavras-chave: Violência, segurança, sociedade do capital.

\section{THE UTOPIA OF SECURITY AND PEACE AMID FEAR AND TERROR FUELED BY A CAPITAL-DOMINATED SOCIETY}

\begin{abstract}
To discuss possibilities for the emergence and installation of security and peace within a society whose civilizing foundation is rooted in fear, violence, terror, making out of them its continued and promising source of conquest, gain,

\footnotetext{
Assistente Social, Doutora em Sociologia pela Universidade Federal do Ceará (UFC), Professora do Mestrado Profissional em Avaliação de Políticas Públicas da Universidade Federal do Ceará (UFC) e do Curso de Serviço Social da Faculdade Metropolitana da Grande Fortaleza (Fametro). E-mail: rejanebvasconcelos@gmail.com / Universidade Federal do Ceará - UFC: Av. da Universidade, 2853 - Benfica, Fortaleza - CE. CEP 60020-181; Faculdade Metropolitana da Grande Fortaleza - Fametro: Rua Conselheiro Estelita No 547, Centro, Fortaleza - CE. CEP: 60010-260
} 
maintenance and existence - that is, the capitalist society - is the goal that this article aims to reach.

Key words: Violence, security, capital-dominated society.

\section{1 "VOCÊ TEM SEDE DE QUE? VOCÊ TEM FOME DE QUE?"1: você tem medo do quê?}

Avalio como produtivo e possível instigar - ainda que, em um primeiro momento, soe prematuro, forçado até - um diálogo com o leitor. Daí o recurso de uma fala inaugural interrogativa que acende o ânimo para uma conversa com o texto mais que - ou para além de - uma leitura do texto. A ideia de assim partir nessa empreitada intelectual irrompe como imperiosa; emana do sentimento, da sensação de que a profusão dos mais diversos e - potencialmente eficientes - meios e instrumentos de comunicação têm deixado a voz - ainda que gritante - inaudível, enfraquecida e, cada vez mais, impingida a fazer-se ato (atuação).

Quer no forçoso calar da voz, quer no abafar contínuo de seu eco, a fala implode em ato - em regra, ato de força -, como nos faz perceber Crettiez (2011, p. 137), quando enfatiza que a violência tem uma pluralidade de significados, mas é um

\footnotetext{
[...] fenômeno que encontra sua unidade na negação do político - aqui entendido como arte civil da convivência -, na recusa da palavra, que ele substitui pela força para se fazer ouvir ou convencer o outro. A violência fascina, nesse caso, porque existe no próprio interior das sociedades modernas, que repousam no culto da comunicação e numa civilização interiorizada.
}

A vontade minha de diálogo, talvez mais a necessidade, possivelmente explique a opção de iniciar a apresentação de minhas ideias trazendo os sujeitos que as leem, com quem as compartilho, para o rol dos interlocutores a falar, a pensar, a construir entendimento acerca do que sustenta a utopia da segurança e da paz sob a bainha na qual a sociedade do capital guarda a espada do terror e do medo.

Dialogar é uma necessidade humana primária, visceral, que, paradoxalmente, tem sido insuficientemente satisfeita nesses tempos de comunicação interceptada por meios e instrumentos que ousam buscar - e às vezes, mantêm - o controle sobre o pensar e o agir humanos. Tempos de um sujeito-meio que deve satisfazer-se exclusivamente em se prestar a pôr em movimento, a dar vida aos 
UTOPIA DA SEGURANÇA E DA PAZ EM MEIO AO MEDO E AO TERROR ALIMENTADOS PELA SOCIEDADE DO CAPITAL

engenhos, às ferramentas, às invenções todas da mais ousada a mais frugal tecnologia.

Esse sujeito, obstinadamente conectado, transmuta-se em equipamento periférico a plugar-se no mundo-computador-rede. Mundo inimaginável há bem pouco, em cujo céu, que deixou de ser tomado como horizonte de seu limite, encontra-se abrigada uma nuvem (one drive) ${ }^{2}$ que guarda seus dados, registros fotográficos e imagéticos, produções intelectuais, comunicações, códigos, senhas, cifras e tudo mais. Algo de existência imaterial a que o sujeito recorre, depositando-lhe integral confiança e a que se submete quase sem reservas. $\mathrm{O}$ sujeito, agora, aliena sua memória; o pouco que ainda resta de seu o entrega ao comando da nuvem: one drive é, assim, um seu fiel depositário. E, doravante, ele passa a viver nas nuvens!

Sem dúvida, a imaterialidade, de forma irrecusável e assombrosa, assume-se enquanto domínio anônimo, sem pessoalidade isto é, sem um agente em que se materialize a origem, a autoria e o exercício deste domínio; dela, todos se tornam reféns. Isso remete àquilo que Kurz (2010) nomina dominação sem sujeito, quando discorre acerca da forma como o capital espraia sua força, sua vontade, sua subjugação a tudo e a todos em todo lugar e tempo: esse imaterial inimigo de muitos e amigo seleto de poucos não tem rosto, mas tem uma sombra, um contorno inconfundivelmente delineado que $o$ identifica e o torna único, onipresente e onipotente.

O mundo cibernético, esse computador global, planetário a que todos desejam e necessitam plugar-se, esse mundo-rede - ou essa rede-mundo - não deixa de, controversamente, apresentar-se como um mundo eremítico, onde sujeitos muitas vezes ilusionam a si mesmos; autopromovem-se; falam de si e para si; fotografam-se (selfies); ilham-se, enquanto clicam o aceite de amigos estranhos, famosos ou anônimos, nominados ou cognominados, que nunca viram ou verão, com quem nunca cruzaram sequer acidentalmente, mas que se encontram numa rede amiga imaginária que quanto mais extensa mais alimenta, mais ilusiona o sujeito em seu inusitado sentimento de pertença. Uma rede onde se lustram egos e aninham-se, não raro, ilusões e delírios de fama e celebração de fantasias.

Orgulhosamente, os sujeitos declaram o número de amigos e seguidores que amealham, minuto a minuto, pelo mundo-rede afora: por todos os continentes do planeta, a amizade se espraia ao simples toque de uma tecla. Nunca foi tão fácil fazer amizade e alimentar um 
pertencimento a uma fantasiosa sociedade de amigos eremitas, e, ao mesmo tempo, circular atônito e sem rumo por entre seus pares, os "[...] membros da multidão de solitários." (IANNI, 2004, p. 107).

Experimentam-se, na contemporaneidade, lugares e tempos de liberdades tanto aprisionadoras quanto cativas. Nela, ampliaram-se, numa velocidade fantástica, meios e recursos que tão bem prestar-se-iam à celebração da fala, do diálogo aberto, amplo, de sons e tons diversos, múltiplos, sonantes e dissonantes.

Nesse tempo e lugar com que nos brinda e castiga a contemporaneidade, ao diálogo é que os sujeitos deveriam sujeitar-se e, por seu intermédio, colocar-se em sua condição de humanidade. Dialogar é ouvir o outro, ao mesmo tempo, em que você também se ouve; é ainda ouvir-se no outro e pelo - por meio do - outro, através do reconhecimento do outro e, igualmente, permitir ao outro realizar-se via essa mesma operação comunicativa. Pois, como alertou Crettiez (2011, p. 30),

Ninguém nasce violento, torna-se. O ingresso na violência, menos do que uma escolha, depende antes de tudo de um contexto em que prevalecem, segundo os analistas, vários estímulos. O primeiro é político e consiste em enfatizar a falta de reconhecimento ou de acesso ao poder por parte de certos grupos, que empregam a violência a fim de obter esse acesso a um Estado distante ou a um reconhecimento, muito deficiente.

Está-se a viver uma existência fluídica. A sociedade vaga absorta, em sua cega e irrestrita rendição ao quimérico delírio da tecnologia que se encerra na plenitude da comunicabilidade solitária, aquela que impinge o sujeito a soliloquiar, a monologar com as questões do seu exclusivo mundo, ao mesmo tempo em que nele alimenta a fábula de que está a pertencer a uma esfera planetária paradisíaca na qual a todos está assegurado o tilintar de taças onde borbulham, em celebração, gotas de safras preciosas.

As redes sociais transfiguram-se em janelas do mundo. E, nessa condição, alimentam a ilusão de transportar o anonimato ao status de instantânea notoriedade, celebridade etérea, o que conduz os que a buscam a uma incessante e insana corrida pelo registro e publicização dos mais banais momentos e eventos da vida cotidiana: uma ida à farmácia, ao cinema, ao supermercado, ao shopping, ao posto de saúde, ao hospital, ao consultório médico, ao colégio, à 
UTOPIA DA SEGURANÇA E DA PAZ EM MEIO AO MEDO E AO TERROR ALIMENTADOS PELA SOCIEDADE DO CAPITAL

faculdade, ou uma simples visita à casa de um familiar ou de pessoa amiga.

Acriticamente, o dia a dia, o corriqueiro é levado, pelas redes sociais, ao conhecimento público; a vida privada demole seus muros, passando a buscar lugar na agenda coletiva, pública. Um lanche, um café com amigos, um almoço, tudo passa pelo apoteosamento. Por consequência, todo e qualquer comentário ou compartilhamento fica sob monitoração. As amizades, os seguidores são submetidos ao espectro do monitoramento. Assim, torna-se ofensiva a falta de um clicar - um curtir ou um compartilhar - em uma postagem feita. O comentário, ainda que marcado tão-somente pela inexpressividade, merece um assinalamento, uma resposta, como garantia da fidelização de novos futuros cliques.

Os que perseguem esse reconhecimento, essa fama e notoriedade voláteis posam sorridentes, saudáveis, felizes, com corpos bem delineados - ou, não os tendo, sob ângulo que não os desfavoreça -; escrevem para si um script e seguem-no à risca, tornando-se dele escravos. Todos anseiam ver sua imagem apresentada nas telas. $\mathrm{E}$ as redes sociais são as que melhor e mais rapidamente dão alimento a esse desejo; elas como que encurtam a distância e o tempo na direção do alcance desse sonho, já que se é patrocinador de sua própria carreira, de sua trajetória. Mas, ao mesmo tempo, elas enevoam as regras que impõem à realização desse desejo sôfrego.

As redes sociais aceleraram o tempo e encurtaram - mas, também aumentaram - distâncias. Aumentaram as distâncias à medida que se começou a prescindir da presença física, em razão do uso das redes sociais para felicitação, informação, manifestação de solidariedade, pêsames - algumas das circunstâncias em que a presença física não se torna dispensável.

As redes sociais consolidaram-se como regente da vida humana, quando deveriam ocupar tão-somente o lugar de ferramentas propiciadoras da comunicação ampla, inteira, diversa, universal; ter como papel primordial o de encurtar espaço e tempo para uma comunicabilidade mais plena, e não para impedi-la, em nome da premência do tempo. Mas o tempo, mais precisamente o controle sobre ele é imperativo do capital. Afinal, tempo é dinheiro! E como dinheiro, fazê-lo render em curto prazo: exigência que sobreleva qualquer outra. 
Lastimável constatar: habitamos um mundo tomado por minúsculos - e gigantescos - aparelhos que nos substituem a fala, o contato, a comunicação direta, a presença física. Enfim, tecnologias por quem estamos sendo substituídos, capturados, subjugados.

$\mathrm{Na}$ comunicação rápida, a palavra dita em sua inteireza pesa como cadáver insepulto, ocupando o tempo e o espaço que já não lhe pertencem mais: com k, k, k, k, k, k ou he, he, he, he, he, he, todos sabem que algo foi dado como engraçado ou que se está rindo de algo; as carinhas, os ícones, os símbolos permitem uma imensurável economia linguística e comunicacional que assegura o aproveitamento do tempo em prol de uma rapidez e diversificação maior de mensagens, de comunicações, bem assim do número de sujeitos por ela alcançados. Afinal, tempo é dinheiro!

Em 24/7 - Capitalismo tardio e os fins do sono, Crary (2014, p. 19-20) assinala que

Um mundo $24 / 7^{3}$ iluminado e sem sombras é a miragem capitalista final da pós-história, de um exorcismo da alteridade, que é o motor de toda mudança histórica.

24/7 é um tempo de indiferença, contra a qual a fragilidade da vida humana é cada vez mais inadequada, e dentro do qual o sono não é necessário nem inevitável. Em relação ao trabalho, torna plausível, até normal, a ideia de trabalhar sem pausa, sem limites.

[...] O sono é uma interrupção sem concessões no roubo de nosso tempo pelo capitalismo. A maioria das necessidades aparentemente irredutíveis da vida humana - fome, sede, desejo sexual e recentemente a necessidade de amizade - foi transformada em mercadoria ou investimento. $\mathrm{O}$ sono afirma a ideia de uma necessidade humana e de um intervalo de tempo que não pode ser colonizado nem submetido a um mecanismo monolítico de lucratividade, e desse modo permanece uma anomalia incongruente e um local de crise no presente global. Apesar de todas as pesquisas científicas, frustra e confunde qualquer estratégia para explorá-lo ou redefini-lo. A verdade chocante, inconcebível, é que nenhum valor pode ser extraído do sono.

É esse nosso modo de existência nessa “[...] 'pólis', a metrópole contemporânea, que já não é cidade mãe, mas praça mercantil "onde se negocia o ser humano", como advertiu Willi Bolle (2000, grifo do autor), ao falar da poesia brechtiana. A contemporaneidade marca-se por essa potencialidade cada vez mais crescente de em tudo 
tocar para transmutá-lo em dinheiro. Sob tal lógica, o ser humano é negociado no atacado ou no varejo, fracionado ou integralmente.

Volto às indagações inicialmente feitas, já não mais na mesma ordem. E a elas, acresço outras: Você tem medo do quê mesmo? Quais são suas fomes e sedes reais? De onde emanam seus medos, suas sedes e suas fomes? As fomes, as sedes, os desejos, as necessidades e os medos experimentados são, de fato, seus ou externamente instituídos, forjados? Do que, realmente, suas sedes e suas fomes necessitam para alcançar saciedade?

\section{A FALA E A ARMA: entre a diplomacia e beligerância}

A convivência humana é, inegavelmente, afligida por situações de conflituosidade, representada por contendas, disputas, divergências de valores, crenças, como está expresso em Étienne e outros (1998, p. 78), na passagem em que dizem que conflitos são

[...] expressão de antagonismos abertos entre os indivíduos ou grupos para a pesquisa, a posse ou a gestão de bens materiais ou simbólicos (riqueza, poder, prestígio, etc.), sendo o objectivo de todo conflito a modificação das relações de força.

Já a violência, na perspectiva de Crettiez (2011, p. 137), é ato de "negação do político" e de "recusa da palavra". Nesse sentido, é um meio de que se vale aquele a quem ficam destinadas a irreconhecibilidade, a invisibilidade e a negativa da condição de sujeito com direitos recíprocos, a despeito do esforço que ele realize para se fazer visível, audível, reconhecido enfim: o sujeito tornado impotente, aquele de quem se aniquilou, de quem se usurpou o poder.

Afirmou Arendt (1985, p. 28) que “[...] a violência é, por sua própria natureza, instrumental; como todos os meios, está sempre à procura de orientação e justificativas pelo fim que busca". Conclui a filósofa que a violência é resultante da impotência e que o poder queda-se diante da violência. Explicitando, com contundência, sua consonância com o pensamento de Arendt (1985), May (1981, p. 17) assevera que "[...] o poder é essencial a todas as coisas vivas".

Desses dois conceitos - conflito e violência - e do que a eles, aqui, foi relacionado, decorre a possibilidade de entender que os caminhos que levam à colocação de termo nos conflitos, isto é, as alternativas à suspensão, finalização ou superação de tais antagonismos, tais contendas, não têm uma via exclusiva, única, significando, 
pois, que, assim como a violência, a diplomacia, a solução política - tomada na perspectiva assinalada por $\operatorname{Crettiez~(2011,~p.~137),~“[...]~}$ como arte civil da convivência." -, põem-se como saída possível para o conflito instaurado, porquanto sejam expressões, disposições, potencialidades, atitudes, atos categorizados - assim como também a violência - como próprios da condição de humanidade do sujeito.

Se a violência emerge e ganha materialidade no sequestro do poder, na instauração da condição de impotência, na cassação da fala do sujeito, impondo, por sua vez, para asseguramento da visibilidade e do sentido de existência do mesmo, a imperiosidade e irrecusabilidade da atuação, do ato para além - e na ausência - da fala, como, então, explicar a forma com que a sociedade contemporânea vem suprimindo os canais de oralidade, de expressão verbal, assim como abdicando do uso apropriado - e com correção - da linguagem escrita e verbal, senão pelo desejo de que esse estado perene de medo, de insegurança, de apavoramento real ou falseado conduza ao exercício efetivo da violência?

Como pensar as razões por que, praticamente, se estimula a eliminação dos canais de comunicabilidade oral, do diálogo presencial - ou mesmo do realizado por meio de telefonia (ligação com comunicação oral) - em prol de mensagens rápidas, cifradas, com substituição de palavras por figuras ou ícones, ao modo da comunicação desenvolvida na mais tenra infância, quando a criança ainda não possui domínio da escrita, e, obviamente, condições para o letramento?

Por que ordem de razão, cada vez mais nos comunicamos com máquinas, a exemplo de quando buscamos solucionar algum problema relacionado aos serviços de informação, às operadoras de telefonia, cartões de crédito, TV por assinatura, planos de saúde, aos Serviços de Atendimento ao Cliente (SACs), às instituições bancárias etc.? Não raro, uma gravação com uma voz, em geral, de mulher impõe a quem busca um desses serviços que fale, em poucas palavras, o que deseja - pois, como se diz popularmente, tempo é dinheiro, logo, falar muito é desperdiçar tempo, é perder dinheiro -, como condição para garantir acesso ao atendimento desejado. Só a partir daí, é que se informa um menu com as opções para que o demandante do serviço continue teclando, conforme os comandos emitidos pela voz. 
Embora existindo normas, emanadas de órgãos de defesa do consumidor, impondo a oferta Falar com atendente como opção primeira, tal não se verifica; o que se observa, em regra, é que esta é a última opção elencada no menu e fica, na maioria das vezes, entre a sétima ou a nona das opções, quando se trata das operadoras.

Por que tem se tornado difícil o acesso à comunicação humana: comunicação de humano para humano; comunicação entre humanos sem interceptação, sem a intermediação compulsória de equipamentos, de máquinas, de gravações que, agora, até simulam uma linguagem mais coloquial?

Ora, estamos na era da comunicação: o mundo virou uma aldeia e o ser humano se ilha? Torna-se eremita nesse planeta plugado? Há algo de estranho no reino da comunicação!

É, pois, oportuno rememorar aquilo que Crettiez (2011, p. 137) destacou em relação ao paradoxo das sociedades modernas que procederam ao endeusamento, à idolatria da comunicação e da redução do tempo e das distâncias comunicacionais, informacionais, mas que estão imersas em práticas havidas nos territórios e tempos em que tais meios e condições não eram sequer imaginadas, daí por que ele afirma que "[...] a violência fascina, nesse caso" - das sociedades modernas.

Por que, sob o império da comunicação, a comunicabilidade, a capacidade argumentativa têm se mostrado, cada vez mais, incapazes de se colocarem como meio de resolução de contendas, isto é, serem a solução política, diplomática para tais situações? Por que a fala está subsumida nessa economia e engenharia comunicacionais? Por que, sob esse império, as falas e a linguagem em sua integralidade tornam-se obsoletas, simplificam-se ou têm abolida a regra ortográfica (rs - risos; abs - abraços; bjs - beijos; obg - obrigado; sdds - saudades; fds - fim de semana; sqn - só que não; vc - você; tc - teclar; vlw - valeu; flw - falou; fikdik - fica a dica; vrdd - verdade; algm - alguém; omg - oh! my God ou ai meu Deus!; axo acho; aki - aqui; ctz - com certeza, entre outras reduções), fazendo ainda emergir um dialeto gráfico empobrecido que sepulta a riqueza, a profundez e a abrangência da linguagem, já alcançadas ao longo dos séculos, em nome da imperatividade do abreviamento do tempo como recurso de evitamento de seu desperdício? 
Uma pista para a construção de respostas e decifração do que parece enigmático: Quanto mais cala, mais atua! Menos falas, mais balas! Mais balas, mais armas. Mais armas, mais Taurus! Mais Taurus, mais lucros!

Essa cadeia econômica, resumidamente, a seguir, apresentada, foi bem descrita ainda no século XIX, do seguinte modo:

\begin{abstract}
Um criminoso produz crimes. Se mais de perto observarmos o entrosamento deste último ramo de produção com a sociedade como um todo, libertar-nos-emos de muitos preconceitos. O criminoso não produz apenas crimes, mas também o direito criminal e, com este, o professor que produz preleções de direito criminal e, além disso, o indefectível compêndio em que se lança no mercado geral "mercadorias", as suas conferências [...] O criminoso produz ainda toda a polícia e justiça criminal, beleguins, juízes e carrascos, jurados e etc.; e todos aqueles diferentes ramos, que constituem outras tantas categorias da divisão social do trabalho, desenvolvem capacidades diversas do espírito humano, criam novas necessidades e novos modos de satisfazê-las. Só a tortura suscitou as mais engenhosas invenções mecânicas e ocupou na produção de seus instrumentos muitos honrados artífices. O criminoso aparece como uma daquelas "compensações" naturais, que restabelecem um equilíbrio adequado e abre uma perspectiva de ocupações "úteis" (MARX, 1987, p. 382-383, grifos do autor).
\end{abstract}

Se o leitor fizer um breve exercício de memória, dar-se-á conta de uma diversidade de categorias e ramos da produção que têm vultosos lucros gerados pelo mercado do crime, pelo mercado da violência: empresas de segurança privada, indústrias de armamentos e munições, rede de terceirização do sistema prisional e penitenciário, empresas de seguro pessoal e patrimonial, indústrias de equipamentos de segurança, mídia, algumas expressões de arte, literatura etc.

Como etapa do mesmo exercício, o leitor poderá buscar entender o espetáculo que tem sido encenado nas distintas Casas Legislativas, marcadamente, no Senado e na Câmara Federal, pela cognominada bancada BBB (bala, boi, bíblia), cuja parte de seus membros, sistematicamente, é protagonista de debates e embates em torno de questões de natureza privada, tais como definiçã $0^{4} /$ orientação sexual, crenças religiosas, e que, não raro, têm sido conduzidos de forma preconceituosa, moralista e, sobretudo, desconsiderando os preceitos constitucionais vigentes. As posturas dos legisladores, nesse particular, têm feito, senão emergir, pelo menos acirrar, no 
seio da sociedade, práticas de intolerância, de preconceito, de ódio e violência contra tudo o que é distinto do seu próprio pensamento, de suas convicções e de seus preceitos morais. Não tem sido incomum, entre alguns desses legisladores, a defesa e indicação de medidas drásticas contra aqueles que são, por eles, classificados como desviantes, quer pelo credo que professam, quer por sua condição sexual (gay, lésbica, transsexual, bissexual, travesti), quer por práticas de transgressões legais. A aversão que desenvolvem contra esses sujeitos manifestam-se tanto de forma velada, quanto aberta e, nesse caso, difundida por todos os meios de comunicação e, mais acentuadamente, na mídia digital.

Integrantes de tais bancadas, representando interesses de segmentos específicos, dentre os quais, igrejas evangélicas, ruralistas, agropecuaristas, latifundiários, indústrias de armamentos e munições - que seriam inclusive, segundo denúncias da mídia, financiadoras de campanhas de vários parlamentares -, têm sido reiteradamente desfavoráveis a demandas da sociedade em geral, legislando em prol dos grupos que thes asseguram assento nessas câmaras legislativas.

Se as investidas no sentido de assegurar a expansão da indústria de armamentos leves e de munições centram-se no esforço de demonstrar tanto a imprescindibilidade do cidadão comum possuir arma de fogo, quanto de se reduzirem os limites proibitivos a esse porte, a esse uso privado, a aposta das empresas administradoras do sistema prisional e penitenciário fica voltada para a redução da idade de responsabilidade penal, hoje, fixada em 18 anos. A Proposta de Emenda Constitucional (PEC) $\mathrm{n}^{\circ} 171$ que rebaixa para 16 anos a maioridade penal foi, em junho de 2015, aprovada na Câmara.

Aos lúcidos, tudo isso soa incoerente: armar para pacificar; declarar, aos quatro cantos, falido tanto o sistema prisional quanto o penitenciário e acirrar os ânimos da sociedade para obter, sem uma maior e mais efetiva reação popular, a subtração de direitos de adolescentes - pobres, é necessário que se frise, pois são esses que, hoje, superlotam os centros educacionais espalhados por todo o território brasileiro, que serão afetados com a medida dos legisladores, tendo em vista que, amanhã, serão exclusivamente eles que, impiedosamente, estarão sendo conduzidos aos presídios e penitenciárias, conferindo maior dimensão ao problema de superlotação que o sistema carcerário enfrenta já há bastante tempo. 
Daí, ser possível afirmar que, no modo capitalista de produzir bens e viver, a violência transfigura-se mercadoria. Logo, a violência, supostamente combatida, é a mesma que é alimentada para entrar no circuito do mercado, como mais uma das mercadorias disponíveis nas prateleiras à disposição do consumidor.

O fato é que a mercadização da violência, do medo, da intranquilidade ganha terreno, auferindo lucros e assegurando fontes sempre renovadas de rentabilidade, quer a violência in natura, quer a que ganha aura de espetáculo, quer a transfigurada em segurança.

Frente a tudo isso, a questão agora a se pensar é: onde situar e como crer possível a utopia da segurança e da paz em meio ao ódio, ao terror, à intolerância, ao medo que a sociedade do capital provoca, promove, difunde, nutre e deles se nutre?

\section{A UTOPIA DE PAZ NA CONCLAMAÇÃO DA GUERRA:} a certeza possível em meio ao terror

Chega, enfim, o momento mais difícil, porquanto delicado: é a vez de falar de utopia. Como um sonho em andamento é, exatamente, meu modo de concebê-la.

Retomando as ideias que, ao longo do artigo, vêm sendo desenvolvidas, consolido-as na afirmação de que o sistema do capital é lúcido, é plástico, é resiliente, e, acima de tudo, voraz, mortífero, e muito longe de ser justo e mais ainda de ser ético - até porque se rege, não pela ética, mas pela lógica, a lógica do lucro -, sendo assim, não haverá razão alguma para que abdique do patrocínio, do fomento, da disseminação das condições efetivas de transformar o planeta em uma arena de disputa, em uma sangrenta praça de guerra onde patrícios ombreiem-se, tornem-se estranhos de seus compatriotas, de seus irmãos e se afinem, aliem-se aos inimigos - muitas vezes, comuns - que fornecem farnel e pólvora para todos os lados que se antagonizam.

E, vencido, o mais fraco que custeie - direta ou indiretamente - a nova próxima batalha. O fato é que: vivos e mortos auferem lucros e promessas futuras de lucros nas novas e velhas guerras por vir. É preciso não esquecer que lucros também se os tem, quando ainda as guerras são tão-somente ameaça.

A contundência emanada das palavras ditas por um filósofo francês contemporâneo, ante o desencanto de uma sombria e incon- 
UTOPIA DA SEGURANÇA E DA PAZ EM MEIO AO MEDO E AO TERROR ALIMENTADOS PELA SOCIEDADE DO CAPITAL

testável realidade, e a quem já havia recorrido na jornada de 2013, para ter encurtada essa travessia do pensamento ao discurso, é oportuna para sintetizar o que expressei sobre as guerras e a rentável promessa em que essas arenas de sangue e cinzas, inexoravelmente, se transformam. "Sem nenhuma prova acreditamos que a paz era o estado natural e a substância do universo e que a guerra era apenas uma agitação temporária que ocorria em sua superfície. Reconhecemos atualmente nosso erro: o fim da guerra é simplesmente o fim desta guerra." (SARTRE, Jean-Paul).

$\mathrm{E}$, mais uma vez, recorro às palavras alheias, fazendo-as minhas, para dizer onde penso que a utopia pode estar adormecida, hibernando, aguardando aflita pelo momento em que a condição de humanidade acenda-se como tocha viva no homem, fazendo-o estranhar-se a si mesmo, e assombrar-se, sentir pavor diante do modo através do qual passou a produzir anomalamente coisas e gentes. É o poeta alemão Bertolt Brecht (2000, p. 129) quem nos vai facilitar esse encontro com a utopia da paz e da segurança.

De que serve a liberdade

Se os livres têm que viver entre os não-livres?

De que serve a razão

Se somente a desrazão consegue o alimento de que todos necessitam?

$[\ldots]$

Em vez de serem apenas livres, esforcem-se

Para criar um estado de coisas que liberte a todos

E também o amor à liberdade

Torne supérfluo!

Em vez de serem apenas razoáveis, esforcem-se

Para criar um estado de coisas que torne a desrazão de um indivíduo

Um mau negócio!

Somente com a transformação da violência em mau negócio, instalar-se-ão as condições para a construção da segurança e da paz na humanidade; quiçá, da existência futura do homem e, mesmo, do planeta.

Como utopia primeira, vale instaurarmos um império: o da fala, para que expressemos com palavras plenas, inteligíveis, sonoras, ásperas ou doces, firmes ou titubeantes tudo o que nos encanta, 
o que nos angustia, o que nos enternece, o que nos apavora, do que precisamos e, sobretudo, o que desejamos, pois como canta o poeta Antunes, em Comida, são muitas as nossas sedes e as nossas fomes. E muitos dos suprimentos das fomes e sedes humanas não encontram colo nas coisas, mas nos sujeitos cuja humanidade necessita, urgentemente, neles ser realojada, acolhida.

Isso é possível nesta civilização do capital?

Com esta indagação, alimentemos, eu e você, leitor, a nossa fome e a nossa sede de diálogo, com as palavras ditas de forma espichada, sem preguiça, sem pressa, em sua inteireza, sem subtrações, pois como o sono não capturado é a inquietação irresoluta e restante - o resta um do jogo - do capital, a palavra dita por inteiro, explicativa e justificadora pode também constituir uma outra fonte de inquietação, por ser capaz de fomentar discórdias dialogais que conduzam ao abalamento das explicações parciais, dos falseamentos todos proclamados como verdades naturais desse modo de arquitetar a existência do planeta com tudo o que ele comporta e todos que o habitam.

Brindemos, pois, as nossas falas!

\section{REFERÊNCIAS}

ARENDT, H. Da violência. Tradução de Maria Cláudia Drummond Trindade. Brasília, DF: UnB, 1985. (Coleção pensamento político).

BOLLE, W. [Orelha]. In: BRECHT, B. Poemas 1913-1956. 5. ed. Tradução de Paulo César de Souza. São Paulo: Editora 34, 2000. Não paginado.

BRECHT, B. Poemas 1913-1956. 5. ed. Tradução de Paulo César de Souza. São Paulo: Editora 34, 2000.

CRARY, J. 24/7 - Capitalismo tardio e os fins do sono. Tradução de Joaquim Toledo Júnior. São Paulo: Cosacnaify, 2014.

CRETTIEZ, X. As formas de violência. Tradução de Lara Christina de Malimpensa; Mariana Paolozzi Sérvulo da Cunha. São Paulo: Loyola, 2011.

ÉTIENNE, J. et al. Dicionário de sociologia: as noções, os mecanismos e os autores. Tradução de Germano Rio Tinto. Lisboa: Plátano Edições Técnicas, 1998. 


\section{UTOPIA DA SEGURANCA E DA PAZ EM MEIO AO MEDO E AO TERROR}

ALIMENTADOS PELA SOCIEDADE DO CAPITAL

IANNI, O. Capitalismo, violência e terrorismo. Rio de Janeiro: Civilização Brasileira, 2004.

KURZ, R. Razão sangrenta: ensaios sobre a crítica emancipatória da modernidade e de seus ocidentais. Tradução de Fernando R. de Moraes Barros. São Paulo: Hedra, 2010.

MARX, K. Teoria da mais-valia. São Paulo: Bertrand, 1987.

MAY, R. Poder e inocência: uma análise das fontes de violência. Tradução de Álvaro Cabral. Rio de Janeiro: Jorge Zahar, 1981.

ONDRIVE. Wikipédia, [20--?]. Disponível em: $<$ https://pt.wikipedia. org/wiki>. Acesso em 25 fev. 2016

\section{NOTAS:}

Trecho da canção Comida de autoria de Arnaldo Antunes.

2 Trata-se de um serviço que possibilita que se armazenem e hospedem arquivos utilizandose de uma Conta da Microsoft. Anteriormente a 27 de janeiro de 2014, esse serviço era denominado Sky drive. (ONDRIVE, [20--?]).

3 24/7 quer, precisamente, dizer 24 horas durante sete dias.

4 Credito como mais adequada a expressão definição sexual, pois esta permite reconhecer que as distintas manifestações e expressões da sexualidade humana são uma condição do sujeito, da qual ele não arreda - nem o pode, já que não está na esfera do arbítrio, da vontade pessoal ou opção -, independentemente das orientações ou imposições sociais que lhe sejam dirigidas. 
